\title{
Nutritional Composition and Therapeutic Benefits of Stevia Leaves: A Mini Review
}

\section{Waseem Khalid ${ }^{1 *}$, Abdul Rehman ${ }^{2}$, Muhammad Irfan ${ }^{3}$, Ravi Prakash Jha $^{4}$, Muhammad Zubair Khalid ${ }^{1}$ and Afifa Aziz ${ }^{1}$}

${ }^{1}$ Institute of Home and Food Sciences, Government College University Faisalabad, Pakistan

${ }^{2}$ University Institute of Diet and Nutrition, The University of Lahore, Pakistan ${ }^{3}$ Department of Food Engineering, University of Agriculture Faisalabad, Pakistan ${ }^{4}$ Department of Community Medicine, Institute of Medical Sciences, Banaras Hindu University, Varanasi, India

*Corresponding Author: Waseem Khalid, Institute of Home and Food Sciences, Government College University Faisalabad, Pakistan.

DOI: $10.31080 /$ ASMI.2020.04.0765
Received: December 21, 2020

Published: January 22, 2021

(C) All rights are reserved by Waseem Khalid., et al.

\begin{abstract}
Nowadays, diabetes is a major issue in the world. The diabetes cases are increasing; peoples have used medicines but due to more side effects, the majority have been using herbal plants for the purpose of cure diabetes. Stevia is considered a sweet herbal plant; it is a natural source of sugar but provides zero calories. The leaves of stevia contain protein, fat, fiber, carbohydrate, antioxidants, phenolic compounds and glycosides. Several studies proved that it can help reduce blood glucose levels. Due to high nutritional composition stevia leaves aid various other diseases.
\end{abstract}

Keywords: Stevia rebaudiana; Diabetes; Sugar

\section{Stevia (Stevia rebaudiana)}

A large eminent as nectar leaf can be used as a piece of tea, refreshments and diverse sustenance are as sweetening administrator [1]. Stevia is a trademark sweetener that does not contribute calories and is 100 times sweeter than sugar. It has been translated into a guide for calorie-perceivers [2].

Stevia is mostly used as a trademark sweetener, a central fragment that is removed and removed from that leaf of stevia. It contains three glucose atoms associated with the steviol moiety [3]. Stevia is also called Stevia rebaudiana, it is a plant that is a member of the chrysanthemum family which is a subgroup of the Asteraceae family (ragweed family). The stevia bought from the grocery store and the stevia grown at home is very different from each other. Stevia products which are available in the grocery stores like Tuvia and the stevia in raw form are not the original leaves. These are made from highly refined stevia leaf extract which is called rebaudioside. Many products claiming stevia actually have very little stevia in them Reb-A is 200 times sweeter than table sugar [4]. Figure 1 shows the structure of plant, fresh, dry and powder form of stevia leaves.

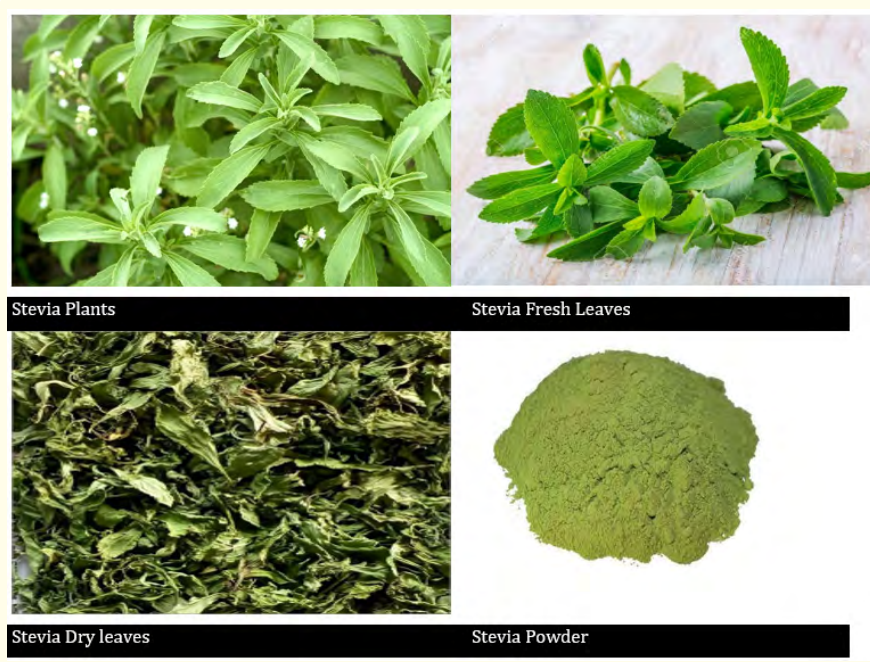

Figure 1: Stevia Plant and Leaves. 
The added sugar in the American diet contributes about $16 \%$ of total calories. This causes weight gains and less control of the glucose level. Stevia contains not any amount of sugar and no calories. It can be used in a diet to reduce body weight without any change or loss in taste. Globally, stevia is used in more than 5,000 food and beverage products nowadays. Throughout Asia and South America, due to the sweetening properties of stevia, it is used as sweetening ingredients in many products [5]. Stevia has the potential to treat endocrine diseases like diabetes, obesity and hypertension [6].

\section{Chemical composition}

Stevia is chemically composed of protein, fat, carbohydrate, ash and fiber. The researchers are used different techniques for the composition of stevia leaves extract such as GC-MS [7]. The sweet leaves of stevia (Stevia rebaudiana Bertoni) have been investigated by many researchers, is used for many years by South America and they call it "Kaa-hee" (Sweet herb). Due to the chemical composition and sweetening properties stevia is used as an alternative to synthetic sweetener. The nutritional and compositional benefits of Stevia rebaudiana are studies nowadays [8]. Chemical composition is shown in table 1.

\begin{tabular}{|c|c|c|c|c|c|}
\hline \multirow{2}{*}{ Year } & \multicolumn{5}{|c|}{ Nutritional Components } \\
\cline { 2 - 6 } & Carbohydrate & Protein & Fat & Ash & $\begin{array}{c}\text { Dietary } \\
\text { fiber }\end{array}$ \\
\hline $\begin{array}{c}\text { El-Nassag., et al. } \\
\text { [9] }\end{array}$ & 66.50 & 9.63 & 3.47 & 3.08 & 17.12 \\
\hline Atteh., et al. [10] & -- & 16.0 & 2.60 & 15.5 & 6.8 \\
\hline $\begin{array}{c}\text { Abou-Arab., } \\
\text { et al. [11] }\end{array}$ & 61.9 & 11.4 & 3.73 & 7.41 & 15.5 \\
\hline Serio [12] & 53 & 11.2 & 5.6 & -- & 15 \\
\hline $\begin{array}{c}\text { Goyal and } \\
\text { Samsher [13] }\end{array}$ & -- & 11.2 & 1.9 & 6.3 & 15.2 \\
\hline
\end{tabular}

Table 1: Nutritional Composition of Stevia Leaves on Dry Matter (g/100g DW).

\section{Phytochemical of Stevia rebaudiana}

Stevia rebaudiana plant is a convenient source of protein $(11.4 \%$ $\mathrm{dw}$ ), starch (69.9\% dw), fibre (15.5\% dw) and minerals (K, Ca, Na, $\mathrm{Mg}, \mathrm{Cu}, \mathrm{Mn}, \mathrm{Fe}$, and $\mathrm{Zn})$. It is a vital source of amino acids recognized by FAO and WHO [14].
Savita., et al. [15] described the nutritional composition of stevia in dry form. They found total carbohydrates, protein, fat, red hot residue and irritating fibrous substances. Stevia leaves are also contained 0.02 grams of oxalic acid [16], and a sweet glycoside mixture [17].

Milani., et al. [18] was found that stevia is the source of stevioside (5-10\%), duloside (0.4-0.7\%) and rebaudiana (1-2\%). Its leaves in dry form contain alkaloids, flavonoids, lutein, chlorophyll, hydroxycyanate, oligosaccharides, amino acids, free sugars and late segments.

\section{Vitamins and Minerals}

Stevia contains many vitamins included vitamins A, C and vitamins of B-complex like thiamine and riboflavin [1]. A previous study was shown that stevia contains water-soluble vitamins such as vitamin $C$ and vitamin $B$ complex. In leaves, folic acid was a major compound and after that vitamin $\mathrm{C}$ is found in a major concentration [19].

Stevia is also a source of some major or minor minerals. Along with nutrition, it is also used in the health and cosmetic industries due to the effectiveness of its phytochemical content. A survey was performed in a study in which plant samples were collected from the province Aydin in Turkey and then their mineral content was determined (N, K, P, Mg, Ca, Cu, Na, Fe, Mn and Zn) [20].

Stevia in unprocessed form is highly nutritious having vitamins and minerals included vitamin $\mathrm{C}$, niacin, magnesium, calcium, chromium, zinc, potassium and phosphorus are shown in table 2 . The stevia leaves contain protein, fibre and at least 100 phytonutrients [21].

Stevia contain minerals included magnesium, calcium, iron and phosphorous. The minerals are beneficial for cardiovascular system, bone formation and porosity against bone and important for bone formation. The minerals present in stevia leaves are beneficial for immune system. Zinc and selenium are the trace minerals present in stevia products. While, many other trace minerals are 


\begin{tabular}{|c|c|c|c|}
\hline \multicolumn{2}{|c|}{ Vitamin Kim., et al. [22]; Blades and Zubr [23] } & \multicolumn{2}{c|}{ Mineral Chughtai., et al. [24] } \\
\hline Water soluble & Contents (mg/100 g) & Mineral & Contents (mg/100 g) \\
\hline Vitamin C & 14.97 & $\mathrm{Na}$ & 29.4 \\
\hline Vitamin B2 & 0.43 & $\mathrm{~K}$ & 2195.3 \\
\hline Vitamin B6 & 1.90 & $\mathrm{P}$ & 372.1 \\
\hline Folic acid & 52.18 & $\mathrm{Mg}$ & 286.2 \\
\hline Niacin & 194 & $\mathrm{Fe}$ & 24.29 \\
\hline Thiamine & 18.8 & $\mathrm{Zn}$ & 1.423 \\
\hline
\end{tabular}

Table 2: Vitamins and Minerals Contents of Stevia Leaves.

also present in stevia leaves included silicon, chromium, cobalt and manganese which are used in enzymatic processes. These provide function of excretory system, utilization of oxygen, physiological assembly and disassembly of energy safely [25].

Phenolic compounds and antioxidants

The phenolic compounds present in stevia leaves are chlorogenic acids, polyphenol family of esters, hydroxycinnamic acids esters with quinic acid, possessing excellent hydrophilic antioxidant activity and therapeutic properties [26].

The glycosides present in stevia leaves are non-nutritive substitutes of sugar which don't provide any energy on consumption. Besides their sweetening properties, stevia leaves also show antioxidant properties and its sweet diterpenes are reported in the literature [27].

Stevia rebaudiana which is a chrysanthemum herb is used as a vegetable-based sweetening additive in health drinks and many other food products. According to studies, it was investigated that the stevia leaves show antioxidant activity and the presence of bioactive compounds. The analysis shows that stevia leaves contain folic acid $52.18 \mathrm{mg} / 100 \mathrm{~g}$. The stevia contains phenolic and flavonoid contents of $130.76 \mu \mathrm{g}$ catechin and $15.64 \mu \mathrm{g}$ quercetin in leaves and $43.99 \mu \mathrm{g}$ catechin and $1.57 \mu \mathrm{g}$ quercetin in cells of $\mathrm{mg}$ of water extracts, respectively. Pyrogallol is the major phenolic compound present in both leaf and cellular extracts of stevia. Additionally, according to various studies the leaf extracts contain a large number of free radicals, hydroxyl radicals and superoxide anion radical scavenging activities than cellular extract [28].

\section{Glycosides}

Glycoside is basically a molecule in which a sugar group is connected to another functional group by a glycosidic bond. In living organisms, glycosides are performed vital roles. Numerous plants cell store glycosides in an inactive form [29]. The sweet leaves of stevia contain glycosides such as stevioside, steviol, steviolbioside, rebaudioside $A$, rebaudioside $B$, rebaudioside $C$, rebaudioside $D$ and dulcoside $\mathrm{A}$ [30]. Table 3 presented the structure and sweeting level of different type of glycoside in stevia leaves.

\section{Health benefits}

Stevia gives the correct amount of calories and there are signs of human prosperity. According to some progressive clinical examinations, Stevia has different therapeutic properties like cell strengthening and antifungal when used as a different maintenance structure [32]. Stevia gives an exact amount of calories and does not create any symptoms on human wellbeing. As per some ongoing clinical examinations, Stevia has diverse treatment properties (cell reinforcement, antifungal, antimicrobial) when utilized as a part of various sustenance frameworks [33].

Consider the adaptability of stevia and report that it exhibits hyperglycemia, antihypertensive, threatening tumors, combating the effects of running and diuretics, and also helping to lose weight. Stevia leaves are generally used to treat diabetes in various parts of the world [34]. Stevia utilization enormously builds the levels of glucose resilience and low plasma glucose in the grown-up [35]. 


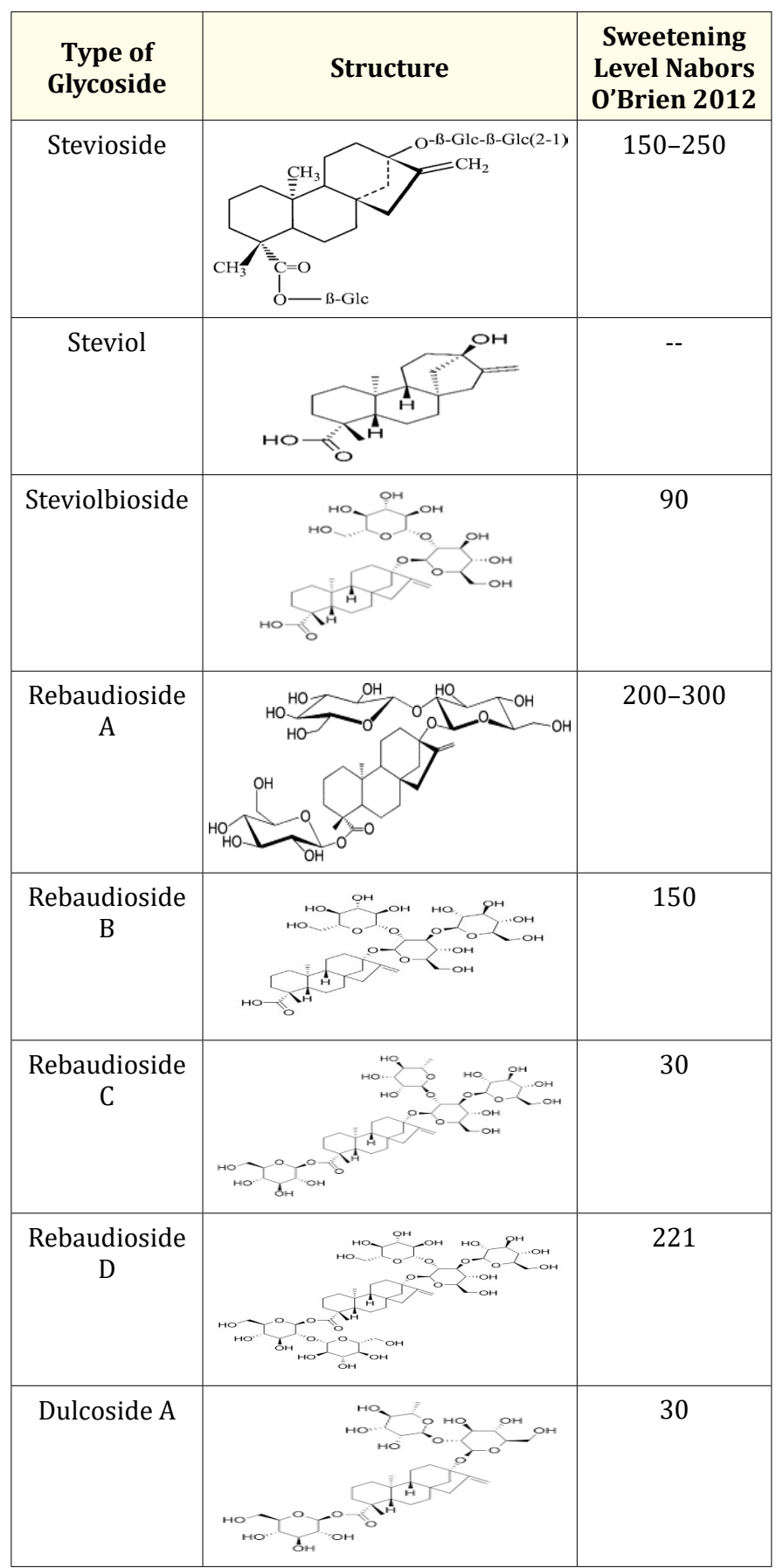

Table 3: Structures and sweetening level of glycoside in Stevia leaves.
Stevia plays a vital role in pancreatic health and can aid in lower hyperglycemia and diabetes. Clinical reports show that glucose levels fall in 35.2\% test points after 6-8 hours utilizing Stevia leaf [36].

Shivanna., et al. [37] was conducted research on diabetes rats. results show that by using stevioside a month and a half a huge increment in insulin response. Aside from hypoglycemic action, stevia diminishes the danger of oxidative pressure. The plant shows a heart tonic movement that helps coordinate heart rate and circulation strain levels. They also found antibacterial, palliative and bacteria-free properties. Stevia exhibits nourishing properties associated with the stomach and exhibits extraordinary effects in removing skin problems such as dermatitis, skin deterioration, and skin irritation [38].

Megeji, Kumar., et al. [34] Little by little, stevia leaves are used throughout the world to treat diabetes. The use of stevia essentially assembles glucose to counteract and reduce plasma glucose levels in adults [39].

Danger can be implied as pain associated with body cells. As the development progresses, cellular DNA is eliminated. Stevia has been used as a substitute for different trademark sweeteners for a long time [13]. Harmful quality has been investigated for stevia for a long time, until now no malignant tumours, genotoxicity or different harmful effects have been found [40]. Different examinations listed the inhibition of stevia removal on tumour changes. Steviosides, stevia glucosides, isosteviol and steviol have become warmer, have slow down properties, and decrease tumour progression by blocking specific antigens [41]. The post-hydrolysis effect of stevioside may lead to DNA replication and unsafe cell progression [42]. Stevia leaves are generally used to treat diabetes in various parts of the world [34]. Stevia utilization enormously builds the levels of glucose resilience and low plasma glucose in a grown-up. Examinations revealed the impacts of blocking stevia on tumour advancement. Stevioside, stevia leaf aglycones, isosteviol and steviol are enamoured with inhibitory properties for the specific antigens obstructing by tumour development [41]. The stevioside hydrolyzed result conceivably prevents DNA duplication as well as carcinogenic chamber development [42]. 
Chatsudthipong and Muanprasat [32] considered the helpful capability of Stevia and detailed that it indicates hostile to hyperglycemic [43], against hypertensive [44], against tumour [45], hostile to the looseness of the bowels and diuretic impacts and helps in weight reduction. The plant demonstrates cardiotonic activity, which helps in the level of heart rate and circulatory strain [46]. They additionally got antibacterial, mitigating and clean properties. Stevia processing indicates tonic properties and shows great outcomes in skin issues, for example, skin ailment [47], skin inflammation, dermatitis and so forth. It is additionally viable for cavity anticipation [28]. Stevia helps to control blood sugar and insulin levels. Stevia leaves extract has been used for many centuries in South America as a medicinal herb used in the treatment of diabetes. Stevia is used to lower blood pressure. According to a study, the oral intake of $250 \mathrm{mg}$ of stevia three times a day for one year causes a decrease in both systolic and diastolic blood pressure of patients suffering from mild to moderate hypertension [48].

An effective remedy for dandruff and acne, stevia contains several antibacterial, antifungal and anti-inflammatory agents that can cope with unpleasant rashes on the face or annoying hair dandruff. Reduce wrinkles and skin lines. Retinoic acid prevents the breakdown of collagen and elastin, thereby regulating wrinkle formation. Besides, Stevia reduces sebum production, increasing the life of skin cells. Relieves digestive problems, plant glycosides have a soothing effect on the irritated gastric mucosa, making it an active ingredient for treating digestive problems and heartburn [49]. Stevia has a favorable effect on blood sugar level, make it effective for patients of type 2 diabetes, those who want to lose weight, use stevia which is a better non-nutritive sweetener [50].

\section{Role in diabetics}

Diabetes mellitus may be cured by using many traditional plants which are preferred as a natural source of drugs because they are quite safe, less toxic than pharmaceuticals and keep strong antioxidant activities. Due to these reasons, these plants are considered to be more effective against diabetes. Stevia rebaudiana Bertoni is a traditional plant that has beneficial due to its sweet effects on blood glucose regulation [51].

\section{Lowering of blood glucose level}

Stevia suppresses plasma glucose levels and raises glucose tolerance better than artificial sweeteners. Stevia also has no calories, which makes it highly beneficial for lowering glucose levels. Sucrose contains calories due to which consumers gain weight after its consumption. Artificial sugars can be replaced with stevia in the sugar-containing products. Stevia is triggered the glucagon response and also reduces blood glucose in people suffering from type 2 diabetes. Glucagon is the hormone that regulates blood glucose levels in the blood. For diabetic patients, the system that produces glucagon is usually faulty [52].

\section{Other medicinal uses}

Stevia has drawn the attention of health-conscious fitness lovers all over the planet as a non-caloric sweetener. It is regarded as replacing saccharin worldwide. The major sweet compounds that are isolated from the stevia leaves are several glycoside compounds including steviolbioside, stevioside, dulcoside and rebaudiosides [50].

According to various studies stevia can reduce the risk of pancreatic cancer by $23 \%$. Intake of stevioside as a supplement can reduce blood pressure. Stevia has also been shown to have anticancer, anti-inflammatory, diuretic and immunomodulatory effects. Being a non-carbohydrate sweetener, stevia would not favor the growth of Streptococcus mutans bacteria in the mouth which is attributed to be a causative agent of dental caries and tooth cavities [53].

\section{Conclusion}

This review concluded that stevia leaves are composed of fat, protein, carbohydrate, vitamins and minerals in a small quantity. Glycosides are chemical compounds naturally present in stevia leaves that responsible for the sweet taste. Its antioxidants and phenolic compounds aid against diseases. Stevia plays a therapeutic role in diabetes by reducing blood glucose. 


\section{Bibliography}

1. Lemus-Mondaca R., et al. "Stevia rebaudiana Bertoni, source of a high-potency natural sweetener: A comprehensive review on the biochemical, nutritional and functional aspects". Food Chemistry 132.3 (2012): 1121-1132.

2. Balaswamy K., et al. "Production of low calorie ready-to-serve fruit beverages using a natural sweetener, stevia (Stevia rebaudiana L.)". Focusing on Modern Food Industry 3 (2014): 59-65.

3. Marcinek K and Zbigniew K. "Stevia rebaudiana Bertoni? chemical composition and functional properties". Acta Scientiarum Polonorum Technologia Alimentaria 14.2 (2015): 145152.

4. Dyduch-Siemińska M., et al. "Stevia rebaudiana Bertoni, a Source of High-Potency Natural Sweetener-Biochemical and Genetic Characterization". Molecules 25.4 (2020): 767.

5. Nachay $\mathrm{K}$ and Melanie ZB. "Ingredient Innovations Evolve". Food Technology 68.8 (2014): 54.

6. Khiraoui AB and Taoufiq G. "Effect of Stevia rebaudiana, sucrose and aspartame on human health: A comprehensive". Journal of Medicinal Plants 6.1 (2018): 102-108.

7. Marković IS., et al. "Chemical composition of leaf extracts of Stevia rebaudiana Bertoni grown experimentally in Vojvodina”. Journal of the Serbian Chemical Society 73.3 (2008): 283297.

8. Marcinek $\mathrm{K}$ and Zbigniew K. "Stevia rebaudiana Bertoni? chemical composition and functional properties". Acta Scientiarum Polonorum Technologia Alimentaria 14.2 (2015): 145152.

9. El-Nassag DE., et al. "Stevia (Stevia rebaudiana) leaves: chemical composition, bioactive compounds, antioxidant activities, antihyperglycemic and antiatherogenic effects". 1.1 (2019).

10. Atteh J., et al. "Potential use of Stevia rebaudiana in animal feeds". Archivos de zootecnia 60.229 (2011): 133-136.
11. Abou-Arab A., et al. "Physico-chemical assessment of natural sweeteners steviosides produced from Stevia rebaudiana Bertoni plant". African Journal of Food Science 4.5 (2010): 269281.

12. Serio L. "La Stevia rebaudiana, une alternative au sucre". Phytothérapie 8.1 (2010): 26-32.

13. Goyal SK., et al. "Stevia (Stevia rebaudiana) a bio-sweetener: a review". International Journal of Food Sciences and Nutrition 61.1 (2010): 1-10.

14. Bondarev N., et al. "Peculiarities of diterpenoid steviol glycoside production in in vitro cultures of Stevia rebaudiana Bertoni". Plant Science 161.1 (2001): 155-163.

15. Savita S M., et al. "Stevia rebaudiana-A functional component for food industry". Journal of Human Ecology 15.4 (2004): 261-264.

16. Allam AI., et al. "Itrogen fertilizer requirements of Stevia rebaudiana bertoni, under Egyptian conditions". Egyptian Journal of Agricultural Research (Egypt) (2001).

17. Yadav AK., et al. "A review on the improvement of stevia [Stevia rebaudiana (Bertoni)]". Canadian Journal of Plant Science 91.1 (2011): 1-27.

18. Milani PG., et al. "Fortification of the whey protein isolate antioxidant and antidiabetic activity with fraction rich in phenolic compounds obtained from Stevia rebaudiana (Bert.). Bertoni leaves". Journal of Food Science and Technology 54.7 (2017): 2020-2029.

19. Khiraoui A., et al. "Nutritional and biochemical properties of natural sweeteners of six cultivars of Stevia rebaudiana Bertoni leaves grown in Morocco". Journal of Materials and Environmental Science 8.3 (2017): 1015-1022.

20. Gasmalla MAA., et al. "Nutritional composition of Stevia rebaudiana Bertoni leaf: effect of drying method". Tropical Journal of Pharmaceutical Research 13.1 (2014): 61-65. 
21. Ahmad J., et al. "Stevia rebaudiana Bertoni.: an updated review of its health benefits, industrial applications and safety". Trends in Food Science and Technology (2020).

22. Kim IS., et al. "The antioxidant activity and the bioactive compound content of Stevia rebaudiana water extracts". LWT-Food Science and Technology 44.5 (2011): 1328-1332.

23. Blades $\mathrm{M}$ and Zubr J. "Carbohydrates, vitamins and minerals of Camelina sativa seed". Nutrition and Food Science (2010).

24. Chughtai MFJ., et al. "Biochemical and nutritional attributes of Stevia rebaudiana grown in Pakistan”. Progress in Nutrition 21 (2019): 210-222.

25. Putnik P., et al. "Sugar reduction: Stevia rebaudiana Bertoni as a natural sweetener". Agri-Food Industry Strategies for Healthy Diets and Sustainability. Academic Press (2020): 123-152.

26. Myint KZ., et al. "Polyphenols from Stevia rebaudiana (Bertoni) leaves and their functional properties". Journal of Food Science 85.2 (2020): 240-248.

27. Lemus-Mondaca R., et al. "Antioxidant, antimicrobial and antiinflammatory potential of Stevia rebaudiana leaves: effect of different drying methods". Journal of Applied Research on Medicinal and Aromatic Plants 11 (2018): 37-46.

28. Kim YA., et al. "Antioxidant phytochemical and quality changes associated with hot water immersion treatment of mangoes (Mangifera indica L.)". Food chemistry 115.3 (2009): 989-993.

29. Blanco G., et al. "In silico approach for unveiling the glycoside hydrolase activities in Faecalibacterium prausnitzii through a systematic and integrative large-scale analysis". Frontiers in Microbiology 10 (2019): 517.

30. Purkayastha S and David K. "Metabolic fate in adult and pediatric population of steviol glycosides produced from stevia leaf extract by different production technologies". Regulatory Toxicology and Pharmacology 116 (2020): 104727.

31. Nabors OL. "Alternative sweeteners". Steviol Glycoside 11 (2012) 159-180.
32. Chatsudthipong V and Chatchai M. "Stevioside and related compounds: therapeutic benefits beyond sweetness". Pharmacology and Therapeutics 121.1 (2009): 41-54.

33. Goettemoeller J and Alejandro C. "Seed germination in Stevia rebaudiana". Perspectives on new crops and new uses. ASHS Press, Alexandria, VA (1999): 510-511.

34. Megeji NW., et al. "Introducing Stevia rebaudiana, a natural zero-calorie sweetener”. Current Science (2005): 801-804.

35. Barba FJ., et al. "Current applications and new opportunities for the use of pulsed electric fields in food science and industry". Food Research International 77 (2015): 773-798.

36. Gülçin İ., et al. "Radical scavenging and antioxidant activity of tannic acid". Arabian Journal of Chemistry 3.1 (2010): 43-53.

37. Shivanna N., et al. "Antioxidant, anti-diabetic and renal protective properties of Stevia rebaudiana". Journal of Diabetes and its Complications 27.2 (2013): 103-113.

38. Gupta E., et al. "Nutritional and therapeutic values of Stevia rebaudiana: A review". Journal of Medicinal Plants Research 7.46 (2013): 3343-3353.

39. Oliveira-Filho RM., et al. "Chronic administration of aqueous extract of Stevia rebaudiana (Bert.) Bertoni in rats: endocrine effects". General Pharmacology: The Vascular System 20.2 (1989): 187-191.

40. Lugemwa FN., et al. "Determination of radical scavenging activity and total phenols of wine and spices: A randomized study". Antioxidants 2.3 (2013): 110-121.

41. Akihisa T., et al. "Microbial transformation of isosteviol and inhibitory effects on Epstein- Barr virus activation of the transformation products". Journal of natural products 67.3 (2004): 407-410.

42. Mizushina Y., et al. "Structural analysis of isosteviol and related compounds as DNA polymerase and DNA topoisomerase inhibitors". Life sciences 77.17 (2005): 2127-2140. 
43. Buniowska M., et al. "Bioaccessibility of bioactive compounds after non-thermal processing of an exotic fruit juice blend sweetened with Stevia rebaudiana". Food chemistry 221 (2017): 1834-1842.

44. Esmerino EA., et al. "The influence of sweeteners in probiotic Petit Suisse cheese in concentrations equivalent to that of sucrose". Journal of Dairy Science 96.9 (2013): 5512-5521.

45. Abdel-Rahman A., et al. "The safety and regulation of natural products used as foods and food ingredients". Toxicological Sciences 123.2 (2011): 333-348.

46. Rocha I Furtado dO and Helena MAB. "Passion fruit juice with different sweeteners: sensory profile by descriptive analysis and acceptance". Food Science and Nutrition 3.2 (2015): 129139.

47. Granato D., et al. "Characterization and comparison of phenolic composition, antioxidant capacity and instrumental taste profile of juices from different botanical origins". Journal of the Science of Food and Agriculture 95.10 (2015): 1997-2006.

48. Shinde MR and Jasmin W. "Effects of stevia and xylitol chewing gums on salivary flow rate, $\mathrm{pH}$, and taste acceptance". Journal of Dental Research and Review 7.2 (2020): 50.

49. Ciriminna R., et al. "A bioeconomy perspective for natural sweetener Stevia". Biofuels, Bioproducts and Biorefining 13.3 (2019): 445-452.

50. Samuel P., et al. "Stevia leaf to stevia sweetener: exploring its science, benefits, and future potential". The Journal of Nutrition 148.7 (2018): 1186S-1205S.

51. Ahmad U and Rabia SA. "Anti diabetic property of aqueous extract of Stevia rebaudiana Bertoni leaves in Streptozotocininduced diabetes in albino rats". BMC Complementary and Alternative Medicine 18.1 (2018): 179.

52. AbdElwahab AH., et al. "Comparative effects of Stevia rebaudiana and aspartame on hepato-renal function of diabetic rats: biochemical and histological approaches". Journal of Applied Pharmaceutical Science 7.8 (2017): 34-42.
53. Sharangi AB and Pemba HB. "Stevia: Medicinal Miracles and Therapeutic Magic". International Journal of Crop Science and Technology 2.2 (2016).

\section{Assets from publication with us}

- Prompt Acknowledgement after receiving the article

- Thorough Double blinded peer review

- Rapid Publication

- Issue of Publication Certificate

- High visibility of your Published work

Website: www.actascientific.com/

Submit Article: www.actascientific.com/submission.php

Email us: editor@actascientific.com

Contact us: +919182824667 